\title{
INDICADORES DE SUSTENTABILIDADE DAS POLÍTICAS PÚBLICAS DECORRENTES DA EXPANSÃO DO SETOR SUCROALCOOLEIRO EM CARMO DO RIO VERDE (GO)
}

\author{
Dayse Mysmar Rodrigues \\ Doutoranda em Ciências Ambientais pela Universidade Federal de Goiás - UFG \\ dmysmar@hotmail.com \\ Estela Najberg \\ Doutora em Administração pela Fundação Getulio Vargas - FGV \\ Professora da Universidade Federal de Goiás - UFG \\ estelanajberg@gmail.com
}

\begin{abstract}
RESUMO
A expansão da cana-de-açúcar no Estado de Goiás é caracterizada pela expansão da fronteira agrícola. No entanto, para que essas mudanças não prejudiquem a sustentabilidade dos municípios é necessário identificar a ferramenta e os indicadores de sustentabilidade capazes de mostrar qual o aspecto (social, ambiental, econômico ou institucional) mais afetado. Com estas informações, é possível verificar se as políticas públicas contemplam a sustentabilidade no município de Carmo do Rio Verde (GO), sede de usina sucroalcooleira na microrregião de Ceres. Este estudo pretende analisar os impactos da expansão do setor sucroalcooleiro para a sustentabilidade regional, para que os agentes públicos possam utilizá-los como indicadores de políticas públicas. A metodologia utilizada para investigação e o levantamento dos dados terão como base as pesquisas documental e de campo; os dados serão tratados com o uso da ferramenta Dashboard of Sustainability, que deverá descrever e explicar o perfil sustentável do município de Carmo do Rio Verde (GO).
\end{abstract}

Palavras-chave: Dashboard of sustainability; Fronteira agrícola; Indicadores de sustentabilidade; Políticas públicas; Setor sucroalcooleiro.

\section{SUSTAINABILITY INDICATORS OF PUBLIC POLICY DUE TO EXPANSION OF THIS SECTOR IN CARMO DO RIO VERDE (GO)}

\begin{abstract}
The expansion of sugar cane crops in Goiás state is characterized by a general agricultural expansion. This expansion resulted in more investment in technological bases and reflects more development. For these changes to not undermine the sustainability of cities, it is necessary to identify the tools and sustainability indicators capable of showing which aspect (social, environmental, economic, or institutional) is most affected. With this information we can check whether the policies include sustainability in the city of Carmo do Rio Verde (GO), the headquarters of the sugar and alcohol company in the micro region of Ceres. The present study aims to demonstrate that the expansion of this sector should be analyzed from various angles, according to the modifications made, in an interdisciplinary way, in order to allow public agents to use this research as an indicator of public policy. The methodology utilized for research and data collection was documentary and field research. The data are further processed in an interdisciplinary way with the quantitative and qualitative use of the tool Dashboard of Sustainability, which should describe and explain the profile of the sustainable city of Carmo do Rio Verde (GO).
\end{abstract}

Key words: Dashboard of sustainability; Frontier agricultural; Indicators of sustainability; Public policy; Sugar cane.

Revista de Gestão Social e Ambiental - RGSA, São Paulo, v. 6, n. 3, p. 61-77, set./dez. 2012. 


\section{INTRODUÇÃO}

Para pesquisar a expansão do setor sucroalcooleiro no Estado de Goiás e seus impactos no desenvolvimento dos municípios sedes de usinas de álcool, é importante analisar as variáveis que afetam as transformações ocorridas, entre elas podem ser destacadas: a nova configuração do uso do solo e seu reordenamento, os impactos socioeconômicos, os programas de sustentabilidade utilizados pelas indústrias canavieiras, a legislação ambiental pertinente, bem como as políticas públicas decorrentes desta expansão.

O Estado de Goiás foi bastante incentivado pelo governo no que tange à produção de canade-açúcar, tanto em relação à implantação de usina nos programa Produzir e Fomentar, quanto em relação à aquisição de usinas já existentes, por meio de subsídio a grupos empresariais, como foi o caso da Vale Verde de Itapuranga, a Cooper-Rubi de Rubiataba e a CRV Usina de Carmo do Rio Verde. Para identificar esse incentivo, é necessário verificar o desenvolvimento da cana-de-açúcar no município, os impactos sobre o caráter sustentável, além de analisar as políticas públicas voltadas à sustentabilidade do Complexo da cana-de-açúcar, conforme estabelecido na - Agenda 21, Capítulo 10, Seção II, Parágrafo 3: "Os governos devem usar as leis, as regulamentações $e$ incentivos econômicos para estimular o uso e a administração sustentável dos recursos do solo".

Primeiro, é necessário mostrar que a expansão do setor sucroalcooleiro se dá em consequência da expansão da fronteira agrícola e pelo aumento da produção em terras já consolidadas, consequentes da cultura capitalista e da modernização agrícola (Miziara, 2006). Da mesma forma, é necessário apresentar a ferramenta Dashboard of Sustainability (Painel da Sustentabilidade), utilizada para o cálculo de sustentabilidade, selecionada entre as quatro mais conhecidas (Bellen, 2006). Esta escolha se deve aos seguintes fatores: a ferramenta contempla quatro dimensões da sustentabilidade (social, econômica, ambiental e institucional); há flexibilidade nas dimensões, que podem ser modificadas de acordo com a necessidade do município a ser analisado, sem alterar a base do sistema; pela facilidade de aplicação e adaptação; e por ser freeware, disponibilizado gratuitamente na internet.

Por último, mostra quais as variáveis necessárias para se avaliar as políticas públicas, sob o prisma da sustentabilidade. Essa informação só será fornecida com os dados levantados acerca das mudanças do espaço físico, causadas pela expansão da fronteira agrícola, do perfil de desenvolvimento sustentável do município e das políticas públicas apresentadas pelo governo municipal. Assim, as variáveis deverão responder se, com a expansão da cana-de-açúcar no município de Carmo do Rio Verde (GO), há utilização de informações pelos agentes públicos para o estabelecimento de políticas públicas visando ao desenvolvimento sustentável.

\section{FUNDAMENTAÇÃO TEÓRICA}

Os estudos realizados sobre fronteira agrícola vêm demonstrando, cada vez mais, os fatores que foram relevantes para a ocupação do solo e a expansão de áreas já ocupadas, bem como as mudanças ocorridas. A primeira fase da expansão, pode ser definida (Martins, 1975; Miziara, 2000) pela frente de expansão destacada por produções não capitalistas, caracterizada pela ocupação de novos espaços disponíveis para iniciar a produção agropecuária de subsistência. Nessa fase, motivados pela ocupação de novos espaços, os pioneiros iniciam uma marcha rumo ao CentroOeste, região considerada uma das mais promissoras. Na segunda fase, caracterizada pela expansão de terras em áreas já ocupadas, as relações capitalistas aparecem e se fortalecem. Nesta etapa, as terras começam a ter um valor monetário e as produções já não são mais trocadas como excedente, mas sim incorporadas à economia de mercado.

Após essas fases de ocupação e de expansão, as áreas já ocupadas (na primeira fase) e comercializadas (na segunda fase) aumentam o seu valor a partir do momento em que disponibilizam mais riquezas. Entre as décadas de 1960 e 1970, ocorreu um reordenamento do espaço produtivo. As conquistas nas áreas da ciência e da tecnologia permitiram o aproveitamento

Revista de Gestão Social e Ambiental - RGSA, São Paulo, v. 6, n. 3, p. 61-77, set./dez. 2012. 
de terras que eram consideradas impróprias para o cultivo. Para Miziara (2006), a fronteira agrícola foi marcada pela modernização tecnológica, identificada como responsável pela conversão de solos de qualidade inferior em terras férteis. Deste modo, houve uma nova expansão da fronteira por áreas que já tinham sido ocupadas para atendimento a interesses capitalistas.

Este modelo, defendido por Miziara (2000), contém elementos que ajudam a explicar o fato de certas áreas, onde as relações capitalistas estão solidamente estruturadas, sofrerem modificações na estrutura produtiva sem mudar essas relações. Isto se deve ao fato de se constituírem como área potencial aquelas onde o nível de inversão de capital é relativamente baixo, dado a certo patamar tecnológico. Convém lembrar que alterações significativas no nível de inversão de renda implicam reestruturações na base produtiva.

A expansão da agricultura moderna no estado de Goiás, a partir de meados da década de 1970, configura o que se chama de fronteira agrícola, e, constitui uma intensificação no uso do solo pelo preço mais baixo das terras na região, decorrente de sua pior localização em relação aos mercados consumidores. Diante dessa caracterização de fronteira agrícola, a microrregião de Ceres foi uma das mais beneficiadas com as Colônias Agrícolas do Estado de Goiás (CANGs), sendo o marco da ocupação do Centro-Oeste.

Os "choques do petróleo" na década de 1970, em especial o segundo, em 1979, impactou fortemente sobre a economia do Brasil, desequilibrando a balança comercial. A brusca elevação dos preços do petróleo fez com que o governo federal implementasse políticas energéticas que tinham como objetivo reduzir o dispêndio líquido de divisas. Uma das principais vertentes dessas políticas foi incentivar fontes alternativas ao petróleo importado e o uso eficiente da energia, destacando-se os seguintes programas: Programa de Produção Antecipada de Petróleo; Programa de Eletrotermia; Programa de Uso Eficiente da Energia - Conserve; Programa Nacional do Álcool - Proálcool; a criação do Instituto do Açúcar e do Álcool (IAA); Planos Nacionais de Desenvolvimento (PNDs); o Programa de Cooperação Nipo-Brasileiro para o Desenvolvimento dos Cerrados - Prodecer; o Programa para o Desenvolvimento dos Cerrados - Polocentro; o Fundo de Participação e Fomento à Industrialização do Estado de Goiás - Fomentar; o Programa de Desenvolvimento Industrial de Goiás - Produzir; e, o Programa Nacional de Melhoramento da Cana de Açúcar - Planalçucar.

Em relação às políticas públicas, seus fundamentos estão nas ciências políticas, sociológicas, econômicas, ambientais, administrativas e legais. Não há que se falar em políticas públicas sem contextualizar o ambiente em que elas estão inseridas, pois elas nasceram para diagnosticar e tratar os problemas públicos (Secchi, 2010). Assim, após a caracterização das políticas públicas, os indicadores serão utilizados para mensurá-las quanto à sustentabilidade municipal.

As políticas públicas orientadas para o alcance do desenvolvimento sustentável devem estar fortalecidas com capacidades políticas do Estado, técnico-administrativas, regulamentatórias e planificadoras, além de promover as capacidades empreendedora, econômica e social dos cidadãos, o que significa não apenas proteger, mas promover o seu desenvolvimento. Assim, deve haver aperfeiçoamento da capacidade de ordenação das relações organizacionais civis, políticas, públicas e privadas; deve haver delegação e descentralização no poder decisório nas áreas técnicoadministrativas; deve-se fugir de esquemas rígidos e engessados na formulação das políticas, procurando adaptar-se às mudanças externas.

Najberg (2003, p.122) menciona que estas políticas devem estar baseadas nos pressupostos de parceria com a sociedade; de capacitação para a gestão local; de articulação intra e intergovernamental, com a convergência e a integração de ações entre os órgãos e os níveis de governo; da flexibilidade para a adequação da oferta de programas e ações às demandas locais, respeitando as diversidades.

No Desenvolvimento Sustentável, Bellen (2006) menciona que esse conceito vem de um longo processo histórico crítico da relação entre a sociedade civil e seu meio natural, podendo ser demonstrada por várias definições. O importante é reconhecer a necessidade de fazer algumas considerações a respeito de crescimento econômico, desenvolvimento e sustentabilidade, pois quando falamos de crescimento estamos nos referindo a uma evolução de algo, que, por sua vez, 
poder estar relacionado com a ideia de progresso, de modernização, de riqueza, ou seja, de crescimento econômico. Esta é a nova maneira de a sociedade se relacionar com o seu ambiente e garantir a sua própria continuidade. Segundo o autor "[...]a formulação de uma definição para o conceito de desenvolvimento sustentável ainda gera diversas interpretações, existindo, segundo alguns autores, um certo grau de consenso em relação às necessidades de se reduzir a poluição ambiental, eliminar os desperdícios e diminuir o índice de pobreza" (Bellen, 2006, p.22 apud Baroni, 1992).

O crescimento econômico, visto por Marx (85/86), embora seja condição necessária para o progresso, nem sempre é condição suficiente para o desenvolvimento verdadeiro. Neste aspecto, segundo Sachs (2003, p. 26), o Desenvolvimento Sustentável é que levará a privilegiar a geração de empregos, postos de trabalho com remuneração adequada; políticas que privilegiem a inserção produtiva e dará ênfase à educação e saúde. Desta forma, o Desenvolvimento Sustentável é "[...] aquele que atende às necessidades do presente sem comprometer a capacidade de as futuras gerações atenderem também as suas" (CMMAD, 1991, p.9).

Por último, vale destacar as ferramentas mais utilizadas para a identificação do desenvolvimento sustentável, considerando as mais importantes variáveis relacionadas com o tema indicadores de desenvolvimento sustentável. Bellen (2006) realizou uma pesquisa com especialistas das organizações governamentais e não-governamentais, instituições educacionais e de pesquisa e instituições privadas, para identificar os três principais sistemas de avaliação de sustentabilidade. A conclusão desse estudo mostrou que os indicadores mais lembrados foram: Ecological Footprint Method (EFM), Dashboard of Sustainability (DS) e Barometer of Sustainability (BS); e, que existe uma grande fragmentação entre os diversos especialistas quanto às metodologias de avaliação.

\section{MÉTODO DE PESQUISA}

A finalidade deste artigo é identificar o perfil sustentável do município de Carmo do Rio Verde, por meio de pesquisa descritiva e explicativa. Segundo Vergara (2008), a pesquisa descritiva expõe características de um fenômeno e estabelece conexões entre as variáveis; e a pesquisa explicativa tem o objetivo de justificar os motivos de um determinado fato, visando esclarecer quais os fatores que contribuem para a ocorrência do fenômeno.

\subsection{Instrumentos de coleta de dados}

As entrevistas realizadas nas usinas sucroalcooleiras tiveram como objetivo verificar a produtividade em 2010, bem como a sustentabilidade em sua região; e também nos órgãos municipal e estadual para obtenção dos dados socioeconômicos. Desta forma, foi possível identificar os indicadores para as políticas públicas utilizadas diante das alterações ocasionadas pela expansão canavieira.

O segundo procedimento de pesquisa a ser utilizado neste trabalho foi a obtenção de informações de fontes secundárias. Com o auxílio do Geoprocessamento (LAPIG) e da ferramenta de sensoriamento remoto foi possível coletar as imagens de satélite do campo de pesquisa determinado - Município de Carmo do Rio Verde (GO) - para identificar as áreas que foram incorporadas pela cana e compará-las com o uso anterior. Também pelo mesmo método, foi possível identificar a influência dos fatores naturais.

\subsection{Quanto ao tratamento dos dados}

A forma de tratamento dos dados é interdisciplinar, quanti-qualitativa e complexa. Segundo Morin (2005), a ciência não é só estudada, ela é feita no dia a dia com um pluralismo metodológico. 
Ainda, conforme o autor, o maior desafio para o pensamento contemporâneo é o de pensar a complexidade, que necessita de redefinir o nosso modo de pensar.

Assim o reflexo de qualquer mudança no meio ambiente é sentido em todas as áreas: social, cultural, ecológica, territorial, econômica, política, etc. não sendo possível mostrar os impactos da expansão canavieira e da fronteira agrícola sem utilizar as disciplinas: de Geografia, para caracterização de solo, fertilidade e topografia, bem como para mencionar as transformações geográficas ocorridas; de Geoprocessamento, para captação de dados sobre a expansão da fronteira agrícola; de Economia, para mostrar o funcionamento das relações capitalistas, do monopólio, dos conceitos de renda, capital, lucro, PIB, etc.; de Administração, para conceituar e analisar as estratégias públicas e sobre gestão; de Sociologia, para analisar e conceituar as relações sociais, IDH, empregabilidade, etc.; de Políticas Públicas, para análise dos planos de governo, da participação social, dos grupos regulamentadores; de Direito, para a identificação da legislação ambiental e de políticas públicas; de Estatística, para a análise e verificação de relações e; e claro, de Ciências Ambientais. Enfim, a interdisciplinaridade contribui na identificação e análise dos impactos da expansão canavieira na região de Ceres.

\subsection{Quanto a escolha da ferramenta}

Entre as ferramentas de cálculo de sustentabilidade mais utilizadas, analisamos quatro: o Ecological Footprint Method (EFM) ou Pegada Ecológica, o Barometer os Sustainability (BS) ou Barômetro da Sustentabilidade, o Orbis e o Dashboard of Sustainability (DS) ou Painel de Sustentabilidade.

Não foi possível utilizar a ferramenta Ecological Footprint Method (Pegada Ecológica), pois um dos objetivos deste trabalho é a verificação da aplicação das políticas públicas diante do perfil sustentável do município. Este método consiste em, basicamente, estabelecer a área necessária para manter uma determinada população (ou um sistema econômico) indefinidamente, fornecendo energia e os demais recursos naturais necessários, além de ter capacidade para absorver os resíduos e ou dejetos deste sistema. Não procura definir o tamanho e qual a população para uma determinada área geográfica considerando apenas a pressão sobre o sistema, mas calcula a área necessária para que uma população possa se manter indefinidamente. Este método verifica a sustentabilidade apenas no quesito ambiental.

O Barometer os Sustainability (Barômetro da Sustentabilidade) não verifica a aplicação das políticas públicas do ponto de vista da sustentabilidade do município. Esta ferramenta avalia conjuntamente quais são os principais componentes de sustentabilidade, associando o índice de bem-estar do ecossistema (identificando as tendências da água, terra, ar, biodiversidade e utilização dos recursos) com o índice de bem-estar humano (identificando os fatores individuais sociais, tais como saúde, educação, desemprego, pobreza, rendimentos, crime, etc.). Essa ferramenta analisa apenas a sustentabilidade social e ambiental.

A ferramenta Orbis apresenta um modelo que poderia ser utilizado neste trabalho, mas como uma ferramenta de comparação; pois também não verifica a aplicação das políticas públicas e da economia no perfil sustentável do município, uma vez que seus indicadores de desenvolvimento são divididos em regional, empresarial e em objetivos de desenvolvimento para o milênio.

Considerando que a análise de desenvolvimento sustentável requer uma abordagem interdisciplinar, foi selecionada a ferramenta que atende a classificação de mais indicadores e que contribui para a discussão de sustentabilidade nos municípios analisados. Diante da descrição de quatro das principais ferramentas utilizadas para indicação de sustentabilidade, o Dashboard of Sustainability (Painel da Sustentabilidade) foi a selecionada para ser aplicada aos indicadores que apresentaremos neste trabalho. Também por contemplar as quatro dimensões consideradas as mais importantes para o conceito de desenvolvimento sustentável: social, econômica, ambiental e institucional; por sua flexibilidade nas dimensões, que podem ser modificadas de acordo com as

Revista de Gestão Social e Ambiental - RGSA, São Paulo, v. 6, n. 3, p. 61-77, set./dez. 2012. 
necessidades do município a ser analisado, sem alterar a base do sistema, aplicação e adaptação; e por ser freeware, disponibilizado gratuitamente na internet.

A leitura dos resultados pelo Dashboard of Sustainability ou Painel da Sustentabilidade é mostrada por meio de cores que representam a contribuição de cada um dos índices setoriais para o cálculo da sustentabilidade. O padrão de cor utilizado pelo sistema varia de vermelho (para o pior desempenho) a verde (para o melhor desempenho), passando por uma escala que inclui vários outros tons de vermelho, cor-de-rosa, branco, amarelo e verde. Assim, por exemplo, quando um índice de sustentabilidade aparece em tom cor-de-rosa para vermelho, este índice pouco contribui para a sustentabilidade, e quando aparece em tom verde claro para verde escuro significa que o índice eleva o nível de sustentabilidade para o município.

No painel, podemos relacionar o município em momentos diferentes, o que possibilitará que sejam fornecidas as informações de crescimento sustentável ou não. Essa ferramenta possibilita também relacionar um município com outro, para identificar o mais sustentável. E por fim, essa ferramenta possibilita a comparação de um município com a região, o Estado, e com o País, para saber em que grau de sustentabilidade encontra-se o município analisado.

\section{ANÁLISE E DISCUSSÃO DOS RESULTADOS}

A presença da indústria sucroalcooleira no município estudado tem trazido benesses, mas também mazelas que afetam, sobretudo, os pequenos agricultores, que antes concentravam suas energias no cultivo da terra e na criação de animais. A princípio, os pequenos agricultores se renderam às propostas de arrendamento total ou parcial de suas terras. Mas conforme se expandiam as áreas de lavoura canavieira, na mesma proporção aumentavam as dificuldades para se desenvolver outro tipo de atividade agrícola, devido à intensa utilização de espaço e recursos naturais por parte da usina sucroalcooleira com a lavoura de cana-de-açúcar.

Em consequência, o efetivo pecuário também decresceu na mesma proporção que diminuíram os espaços outrora utilizados como pastos, limitando o volume de negócios ou impossibilitando a expansão e continuidade da atividade pecuária. O mesmo ocorreu com a plantação de frutas e grãos, havendo, inclusive, exclusão de uma ou outra espécie de lavoura. Foi percebido no município inserção incomum de produção: a criação de búfalos, o que mostra o potencial de diversificação e a capacidade da agricultura familiar de adaptar-se a diferentes alternativas de produção.

Ao propor o modelo que explica a expansão da fronteira agrícola, Miziara (2006) afirma que as ocupações do solo pelas atividades agropecuárias deixaram de ser condicionadas somente pela fertilidade, uma vez que outros fatores, tais como topografia, infraestrutura, transportes, tornaram-se variáveis importantes em razão do desenvolvimento tecnológico. Assim, verifica-se que o crescimento rumo ao Estado de Goiás é justificável, pois a implantação de usinas encontradas em Goiás condiz com o modelo em análise, que representa uma grande vantagem competitiva. A mecanização, a utilização de bases técnicas no setor sucroalcooleiro necessitam de uma declividade baixa, de uma boa infraestrutura que resultem numa diminuição dos custos e no aumento da produtividade do setor.

Quanto às políticas públicas, a intenção foi mostrar algumas já instituídas, visando ao crescimento econômico da produção de cana-de-açúcar. Uma das últimas estratégias políticas realizadas pelo governo brasileiro, visando tranquilizar o setor agropecuário foi o lançamento do Plano Agrícola e Pecuário 2011/2012, no dia 17 de junho de 2011. Este plano objetiva o crescimento da produção de forma sustentável e é voltado para a renovação ou ampliação dos canaviais, concedendo uma linha de crédito de até R 1 milhão por safra, com prazo de cinco anos para pagar. Assim, o governo espera colocar um ponto final no problema da escassez do etanol que demonstra uma demanda crescente em razão da expansão dos carros flex. Este plano traz ao setor

Revista de Gestão Social e Ambiental - RGSA, São Paulo, v. 6, n. 3, p. 61-77, set./dez. 2012. 
possibilidade do uso de tecnologia tanta para a melhoria quanto para a dinamização das lavouras o aumento da produtividade, que intensifica a expansão da fronteira agrícola.

No Estado de Goiás, foi incluída na agenda política, no dia 03 de junho de 2011, o estudo da Federação das Indústrias do Estado de Goiás (FIEG). Juntamente com o Fórum Empresarial Goiano, o governo Estadual e Federal e as principais universidades do Estado lançaram o projeto 'Construindo Juntos o Futuro do Agronegócio Goiano'. Este estudo visa analisar as cadeias produtivas do agronegócio e construir um diagnóstico estratégico desdobrado em metas, objetivos, indicadores e planos de ação. Inclui o setor sucroalcooleiro na sua primeira etapa, e, deverá avaliar as possibilidades de adensamento das cadeias produtivas e sugerir um conjunto articulado de medidas estratégicas a serem implementadas nos próximos anos com foco no aumento da produção.

Nota-se que, até o presente momento, as políticas públicas visaram ao crescimento da produção, não dando muita ênfase à sustentabilidade e aos impactos sociais, econômicos, ambientais e institucionais. A política pública não pode significar intervenção em atos isolados. Tem que haver uma previsibilidade, clareza e planejamento. Desta forma, são necessárias articulações com o setor público e privado.

O desenvolvimento sustentável é um processo de transformação que ocorre nas dimensões sociais, econômicas, ambientais e institucionais; composto de uma sequência de condições que apresentam evolução positiva ou negativa em função da sustentabilidade. Essa verificação da condição é feita por meio de um acompanhamento em períodos diferentes, para análise do desenvolvimento sustentável e para que seja possível se chegar a um entendimento do que deve ser alcançado com a formulação de políticas públicas.

A apresentação dos índices e dos indicadores para o estudo da sustentabilidade são a base para a construção da ferramenta de avaliação, pois este corresponde a números que indicam a característica pontual de um determinado momento; e o outro tem a função de fornecer mais informações, agregando conjuntamente características qualitativas e quantitativas na análise.

Desta forma, o índice social deve refletir a postura da sociedade em relação à qualidade de vida e às oportunidades de crescimento de cada município, como mostra a Tabela 1.

Tabela 1 - Índice social - variáveis, indicadores e fontes

\begin{tabular}{|c|c|c|}
\hline \multicolumn{3}{|c|}{ ASPECTOS SOCIAIS } \\
\hline Variáveis & Indicadores & Fonte(s) \\
\hline $\begin{array}{l}\text { Densidade Demográfica } \\
\left(\mathrm{hab} / \mathrm{km}^{2}\right)\end{array}$ & $\begin{array}{l}\text { Quantidade de habitantes por } \mathrm{km}^{2} \text {. Relação entre número total } \\
\text { de habitantes e tamanho do município. }\end{array}$ & IBGE \\
\hline Mortalidade Infantil & $\begin{array}{l}\text { Taxa de mortalidade infantil. Quantidade de óbitos em } \\
\text { crianças até } 7 \text { anos de idade, ocorridos e registrados. }\end{array}$ & $\begin{array}{l}\text { DATASUS e IBGE } \\
\text { Cidades }\end{array}$ \\
\hline IDH-M Educação & $\begin{array}{l}\text { Medida pela taxa de alfabetização de adultos (com ponderação } \\
\text { de dois terços), com uma indicação da capacidade de ler e } \\
\text { escrever; e, a taxa de escolarização combinada do primário, } \\
\text { secundário e terciário bruto, com indicação do nível de } \\
\text { educação da creche ao ensino de pós-graduação. Subíndice do } \\
\text { IDH relativo à Educação. }\end{array}$ & IBGE/ INEP \\
\hline IDH-M Longevidade & $\begin{array}{l}\text { É calculada considerando-se as taxas de mortalidade geral e } \\
\text { infantil (segundo a classe de renda), o acesso a serviços de } \\
\text { saúde, saneamento, educação, cultura e lazer, bem como os } \\
\text { índices de violência, criminalidade, poluição do local onde } \\
\text { vive a população. }\end{array}$ & IBGE \\
\hline Ensino Fundamental & $\begin{array}{c}\text { Será observado nesse índice o nível da evasão escolar no } \\
\text { ensino fundamental, utilizando o número de alunos } \\
\text { matriculados. }\end{array}$ & SEPLAN \\
\hline Ensino Médio & $\begin{array}{l}\text { Será observado nesse índice o nível da evasão escolar no nível } \\
\text { de ensino médio, utilizando o número de alunos matriculados. }\end{array}$ & SEPLAN \\
\hline
\end{tabular}

Revista de Gestão Social e Ambiental - RGSA, São Paulo, v. 6, n. 3, p. 61-77, set./dez. 2012. 
Qualidade da educação

Qualidade do ensino básico calculado com base na taxa de

INEP/ MEC/

rendimento escolar (aprovação e evasão) e no desempenho

dos alunos.

Fontes: Adaptado do IBGE (2002); Bellen (2006); Nações Unidas (2007); e Fonseca (2010).

O índice econômico dever refletir a situação econômica de cada município. Bellen (2006, p. 135) destaca os indicadores de fluxo e estoque que podem ser utilizados no Dashboard of Sustainability. A dimensão econômica, a performance econômica, o comércio, o estado financeiro, o consumo de materiais, o consumo de energia, a geração e gestão de lixo, o transporte, são apresentados nas variáveis da Tabela 2.

Tabela 2 - Índice econômico - variáveis, indicadores e fontes.

\section{ASPECTOS ECONÔMICOS}

Variáveis

Indicadores

Fonte(s)

IDH-M Renda indicador renda per capita média e o PIB per capita anual (em dólares)

do Brasil.

Calculado pelo Coeficiente de Gini de distribuição de renda. Mede oIBGE Cidades

Desigualdade

distribuição

renda

grau de desigualdade existente na distribuição de indivíduos segundo a

$\mathrm{de}^{\mathrm{renda}}$ domiciliar per capita. Seu valor varia de 0 , quando não há

desigualdade (a renda de todos os indivíduos tem o mesmo valor), a 1, quando a desigualdade é máxima (apenas um indivíduo detém toda a renda da sociedade e a renda de todos os outros indivíduos é nula).

Produção de cana-Valor calculado pela quantidade de área destinada ao cultivo da cana-SEPLAN de-açúcar (ha) de- açúcar no município

É um dos indicadores mais utilizados na macroeconomia e tem oIBGE objetivo de mensurar a atividade econômica de uma região. Representa

PIB a soma (em valores monetários) de todos os bens e serviços finais produzidos no município durante um período determinado (neste caso, ano).

Calculado dividindo-se o valor do PIB pelo número da população,IBGE obtendo-se um valor médio per capita. $\mathrm{O}$ valor per capita foi o primeiro indicador utilizado para analisar a qualidade de vida em um país. Países

PIB per capita podem ter um PIB elevado por serem grandes e terem muitos habitantes, mas seu PIB per capita pode resultar baixo, já que a renda total é dividida por muitas pessoas, como é o caso da Índia ou da China.

Relação entre o número de pessoas economicamente ativas. No Brasil,IBGE/ SIDRA além do IBGE, a Fundação Sistema Estadual de Análise de Dados (Seade) e o Departamento Intersindical de Estatística e Estudo

Taxa de emprego Socioeconômicos (Dieese) medem a taxa de desemprego. O IBGE utiliza o critério de desemprego aberto, no qual somente as pessoas que no período de referência estavam disponíveis para trabalhar e realmente procuraram trabalho são consideradas desempregadas.

Renda média Valor do rendimento nominal médio mensal das pessoas IBGE/ SIDRA economicamente ativas. Equivale ao valor médio per capita calculado pelo IBGE

Fonte: Adaptado do IBGE (2002); Bellen (2006); Nações Unidas (2007); e Fonseca (2010).

O índice ambiental deve ser considerado um dos mais relevantes. Neste índice, Bellen (2006, p. 135) destaca os indicadores de fluxo e estoque que podem ser utilizados no Dashboard of Sustainability: a mudança climática, a depleção da camada de ozônio, a qualidade do ar, as áreas de agricultura, de florestas, de desertificação, urbanizadas, de zona costeira, a pesca, a quantidade de

Revista de Gestão Social e Ambiental - RGSA, São Paulo, v. 6, n. 3, p. 61-77, set./dez. 2012. 
água, a qualidade da água, o ecossistema, e, as espécies. Utilizaremos os índices dos objetivos do Milênio, pontuando negativamente para cada ocorrência impactante observada na Tabela 3.

Tabela 3 - Índice ambiental - variáveis, indicadores e fontes.

\begin{tabular}{|c|c|}
\hline \multicolumn{2}{|r|}{ ASPECTOS AMBIENTAIS } \\
\hline Variáveis & Indicadores \\
\hline $\begin{array}{l}\text { Preservação da } \\
\text { Biodiversidade }\end{array}$ & $\begin{array}{l}\text { Degradação de áreas protegidas, queimadas, } \\
\text { desmatamento, redução de pescado, etc }\end{array}$ \\
\hline Fatores Climáticos & Atividades agrícolas prejudicadas \\
\hline Recursos Hídricos & $\begin{array}{l}\text { Assoreamento do corpo d'água, poluição dos rios, } \\
\text { nascentes, escassez do recurso de água, etc. }\end{array}$ \\
\hline Qualidade do Ar & $\begin{array}{l}\text { Geoprocessamento, } \\
\text { ODM, IBGE }\end{array}$ \\
\hline $\begin{array}{l}\text { Aterro sanitário e Coleta } \\
\text { seletiva }\end{array}$ & Existência de aterros sanitários e se há coleta seletiva \\
\hline Estado do Solo & $\begin{array}{l}\text { IBGE/ SEPLAN/ } \\
\text { Pesquisa de campo }\end{array}$ \\
\hline \multicolumn{2}{|c|}{$\begin{array}{l}\text { Fonte: IBGE (2002); Bellen (2006); Nações Unidas (2007); e Fonseca (2010), adaptados pela autora } \\
\text { O índice institucional reflete a estrutura, a dinâmica e o funcionamento das instituições } \\
\text { públicas municipais, como mostra a Tabela } 4 \text {. }\end{array}$} \\
\hline \multicolumn{2}{|c|}{ Tabela 4 - Índice institucional - variáveis, indicadores e fontes. } \\
\hline \multicolumn{2}{|c|}{ ASPECTOS SOCIAIS } \\
\hline Variáveis & Indicadores \\
\hline Gestão Democrática & $\begin{array}{l}\text { Considera a existência de Conselhos Municipais para aPesquisa de campo } \\
\text { estão democrática municipal avaliada pela sua existência, } \\
\text { aridade e atividades realizadas nos últimos } 12 \text { meses. }\end{array}$ \\
\hline $\begin{array}{l}\text { Responsabilidade } \\
\text { Fiscal }\end{array}$ & $\begin{array}{l}\text { Considera o déficit ou superávit orçamentário, ou seja, se aIBGE } \\
\text { eceita municipal supera seus gastos, devendo configurarSEPLAN } \\
\text { omo positiva para o superávit e negativa para o déficit }\end{array}$ \\
\hline $\begin{array}{l}\text { Planejamento } \\
\text { Municipal }\end{array}$ & $\begin{array}{l}\text { Considera a existência de Plano Diretor definido noPesquisa de campo } \\
\text { nunicípio. }\end{array}$ \\
\hline Políticas Públicas & $\begin{array}{l}\text { Considera a democracia participativa e da atuação dasSEPLAN/ Pesquisa de } \\
\text { olíticas públicas em relação à preocupação com ocampo } \\
\text { lesenvolvimento sustentável. Será pontuado para cada } \\
\text { olítica direcionada à sustentabilidade. }\end{array}$ \\
\hline
\end{tabular}

Fonte: IBGE (2002); Bellen (2006); Nações Unidas (2007); e Fonseca (2010), adaptados pela autora

O indicador institucional merece alguns esclarecimentos, já que seus índices são baseados em políticas e gestão públicas, e segundo o IPEA (2010, p. 667), a avaliação de políticas públicas ou programas desenvolvidos por instituições públicas "não constitui tarefa simples. Para tal, existem diversas ferramentas à disposição dos avaliadores, cada qual ancorada em distintas tradições e perspectivas teórico-metodológicas".

Desta forma, foram desenvolvidos para este trabalho os índices apresentados na Tabela 5 que vão compor o indicador institucional. O item de gestão democrática irá trabalhar com índices de existência ou não de conselhos municipais e suas atividades realizadas no último ano da pesquisa. Assim, a verificação da existência de grupos de interesse e de projetos relacionados à conservação do meio ambiente e à preocupação com a expansão da cana-de-açúcar, bem como a físcalização por parte destes grupos, são fundamentais.

Já a responsabilidade fiscal será verificada em relação ao déficit ou superávit na balança comercial municipal, sendo positivo para o superávit. O planejamento municipal será pontuado positivamente para a existência de um plano diretor, definido com participação democrática. 
Por último, as políticas públicas serão pontuadas positivamente em relação aos seus atores: se os políticos têm projetos relacionados à conservação do meio ambiente e à preocupação com a expansão da cana-de-açúcar; se a quantidade de servidores, em relação à quantidade de burocratas, é maior ou menor do que os designados; os juízes, se no último ano manifestaram favoravelmente em algum processo relacionado ao meio ambiente ou a expansão da cana; o Ministério Público, da existência de ação ou projeto de conservação do meio ambiente ou de preocupação com a expansão da cana-de-açúcar; e a existência ou não de veículos de mídia no município, visto que em um ano quantas atividades foram realizadas em prol da conservação do meio ambiente e voltadas quanto a preocupação com a expansão da cana-de-açúcar. Em relação ao ciclo de políticas, o questionamento se dá em face de seguir ou não a estrutura metodológica apresentada, se há critério de urgência para desenvolvimento de política pública, e nas últimas políticas públicas implementadas quanto tempo em média durou da identificação do problema à sua implementação (quanto menor o tempo melhor para o índice).

Tabela 5 - Método para pontuação dos indicadores institucionais municipais

ÍNDICE

INDICADOR

\begin{tabular}{llr}
\hline GESTÃO & Existe algum conselho municipal. & 1 ponto positivo para cada conselho \\
\cline { 2 - 3 } & $\begin{array}{l}\text { Se sim, quantas atividades realizadas } \\
\text { último ano. }\end{array}$ & $\begin{array}{c}\text { no1 ponto positivo para realização de } \\
\text { atividades; } 0 \text { ponto para não realização }\end{array}$
\end{tabular}

\begin{tabular}{lll}
\hline RESPONSABILIDA & Déficit & 0 para déficit \\
DE FISCAL & Superávit & 1 ponto positivo para superávit
\end{tabular}

PLANEJAMENTO

Existe de Plano Diretor 1 ponto positivo para sim

MUNICIPAL Se sim, houve participação democrática da1 ponto positivo para a representação população em sua elaboração. democrática

Os políticos têm projetos relacionados à1 ponto positivo para cada projeto

conservação do meio ambiente e à

preocupação com a expansão da cana-de-

açúcar

Existem servidores burocratas (efetivos) emResultado da quantidade de servidores maior quantidade que os servidoresdesignados divididos pelos burocratas. designados (comissionados) Quanto menor melhor.

Houve atuação dos juízes, no último ano, 1 ponto positivo para cada processo do manifestando-se favoravelmente em algummunicípio x usina;

processo relacionado ao meio ambiente ou à

POLÍTICAS expansão da cana

PÚBLICAS

No Ministério Público, existe de ação ou1 ponto positivo para cada atuação do MP projeto de conservação do meio ambiente ou de preocupação com a expansão da canade-açúcar

Existe algum tipo de veículo de mídia no1 ponto positivo para sim município

Se sim, em um ano quantas atividades1 ponto positivo para cada veículo foram realizadas para divulgar 
favoravelmente a conservação do meio

ambiente e para destacar a preocupação com

a expansão da cana-de-açúcar.

$\mathrm{O}$ ciclo de políticas públicas segue uma1 ponto positivo para sim - O ponto para estrutura metodológica apresentada. não

Há critério de urgência para1 ponto positivo para sim desenvolvimento de política pública

Nas últimas políticas públicasCada dia equivale a um ponto positivo implementadas quanto tempo, em média,quanto menor melhor

durou a identificação do problema quanto à

sua implementação

Fonte: A autora em pesquisa de campo.

Nota: O indicador é criado a partir da soma simples das respostas

Durante a pesquisa de campo, verificou-se em Carmo do Rio Verde que a usina fornece emprego em três turnos. No governo municipal, não há secretaria de meio ambiente, motivo pelo qual não há também projetos relacionados à conservação do meio ambiente, sendo a usina responsável pelos últimos projetos realizados no município. O município apresenta aterro sanitário, mas ainda não possui coleta seletiva. A população participa pouco dos conselhos comunitários, se manifesta apenas para 'reclamar' quanto à queima da cana, ao movimento no anel viário pela circulação de caminhões e ao mau cheiro da vinhaça. O Ministério Público, como representante da comunidade e como órgão de fiscalização, é quem atua diretamente na vigilância do matador, dos lixões, do meio ambiente, etc., mesmo com sua participação sendo representada somente uma vez por semana, pois a presença semanal é do promotor e não do Órgão que continua fiscalizando e controlando a vigilância. As notícias são divulgadas pela rádio comunitária e pelo carro de som. Em relação às políticas públicas, o critério de urgência é visto, mas não é minimizado em dias para aprovação de lei, a média para que um projeto seja aprovado e implementado é de 50 dias.

Tabela 6 - Pesquisa dos aspectos institucionais de Carmo do Rio Verde 


\begin{tabular}{|c|c|c|c|c|}
\hline & \multirow[b]{2}{*}{ ÍNDICE } & \multirow[b]{2}{*}{ INDICADOR } & \multicolumn{2}{|c|}{ CARMO DO RIO VERDE } \\
\hline & & & 2005 & 2010 \\
\hline \multirow{2}{*}{ GESTÃo DEMOCRÁTICA } & Existe algum conselho municipal. & 1 ponto para cada conselho $(+)$ & 10,00 & 13,00 \\
\hline & $\begin{array}{l}\text { Se sim, quantas atividades } \\
\text { realizadas no último ano. }\end{array}$ & $\begin{array}{l}1 \text { ponto para realização de } \\
\text { atividades }(+)\end{array}$ & 1,00 & 1,00 \\
\hline \multirow[b]{2}{*}{ RESPONSABILIDADE FISCAL } & Déficit & 1 para déficit $(-)$ & 0,00 & 0,00 \\
\hline & Superávit & 1 ponto para superávit & 0,00 & 1,00 \\
\hline \multirow[b]{2}{*}{ PLANEAMMENTO MUNICIPAL } & Existe de Plano Diretor & 1 ponto para sim & 0,00 & 0,00 \\
\hline & $\begin{array}{l}\text { Se sim, houve participação } \\
\text { democrática da população em sua } \\
\text { elaboração. }\end{array}$ & $\begin{array}{l}1 \text { ponto para participação } \\
\text { democratica }(+)\end{array}$ & 1,00 & 1,00 \\
\hline \multirow{10}{*}{ POLÍTICAS PÚBLICAS } & $\begin{array}{l}\text { Os políticos têm projetos } \\
\text { relacionados à conservação do } \\
\text { meio ambiente e à preocupação } \\
\text { com a expansão da cana-de-açúcar }\end{array}$ & $\begin{array}{l}1 \text { ponto positivo para cada } \\
\text { projeto }(+)\end{array}$ & 0,00 & 0,00 \\
\hline & $\begin{array}{l}\text { Existem servidores burocratas em } \\
\text { maior quantidade que os servidores } \\
\text { designados }\end{array}$ & $\begin{array}{l}\text { Porcentagem de designados } \\
\text { por burocratas }\end{array}$ & 5,00 & 9,28 \\
\hline & $\begin{array}{l}\text { Houve atuação dos juízes, no último } \\
\text { ano, manifestando favoravelmente } \\
\text { em algum processo relacionado ao } \\
\text { meio ambiente ou a expansão da } \\
\text { cana }\end{array}$ & $\begin{array}{l}1 \text { ponto positivo para cada } \\
\text { processo do municipio } x \text { usina } \\
(+)\end{array}$ & 5,00 & 4,00 \\
\hline & $\begin{array}{l}\text { No Ministério Público existe de ação } \\
\text { ou projeto de conservação do meio } \\
\text { ambiente ou de preocupação com a } \\
\text { expansão da cana-de-açúcar }\end{array}$ & $\begin{array}{l}1 \text { ponto positivo para cada } \\
\text { atuação do MP (+) }\end{array}$ & 2,00 & 5,00 \\
\hline & $\begin{array}{l}\text { Existe algum tipo de veículo de } \\
\text { mídia no município }\end{array}$ & $\begin{array}{l}1 \text { ponto para sim - O ponto para } \\
\text { não }(+)\end{array}$ & 1,00 & 1,00 \\
\hline & $\begin{array}{l}\text { Se sim, em um ano quantas } \\
\text { atividades de divulgação em prol da } \\
\text { conservação do meio ambiente e à } \\
\text { preocupação com a expansão da } \\
\text { cana-de-açúcar houve. }\end{array}$ & 1 ponto para cada veículo $(+)$ & 2,00 & 2,00 \\
\hline & $\begin{array}{l}\text { O ciclo de políticas públicas segue } \\
\text { uma estrutura metodológica } \\
\text { apresentada }\end{array}$ & $\begin{array}{l}1 \text { ponto para sim - O ponto para } \\
\text { não }(+)\end{array}$ & 0,00 & 0,00 \\
\hline & $\begin{array}{l}\text { Há critério de urgência para } \\
\text { desenvolvimento de política pública }\end{array}$ & 1 ponto para sim (+) & 0,00 & 0,00 \\
\hline & $\begin{array}{l}\text { Nas últimas políticas públicas } \\
\text { implementadas quanto tempo em } \\
\text { média durou da identificação do } \\
\text { problema à sua implementação }\end{array}$ & $\begin{array}{l}\text { ponto por dias - quanto maior } \\
\text { pior (-) }\end{array}$ & 40,00 & 45,00 \\
\hline & \multicolumn{2}{|l|}{ TOTAL } & $-25,00$ & $-23,72$ \\
\hline
\end{tabular}

Fonte: Elaborada pela autora

Quanto aos resultados encontrados em relação à espacialização da cana-de-açúcar, Carmo do Rio Verde mostrou um crescimento de, aproximadamente, $28 \%$ na área de cana-de-açúcar, conforme se verifica na Figura 1. 


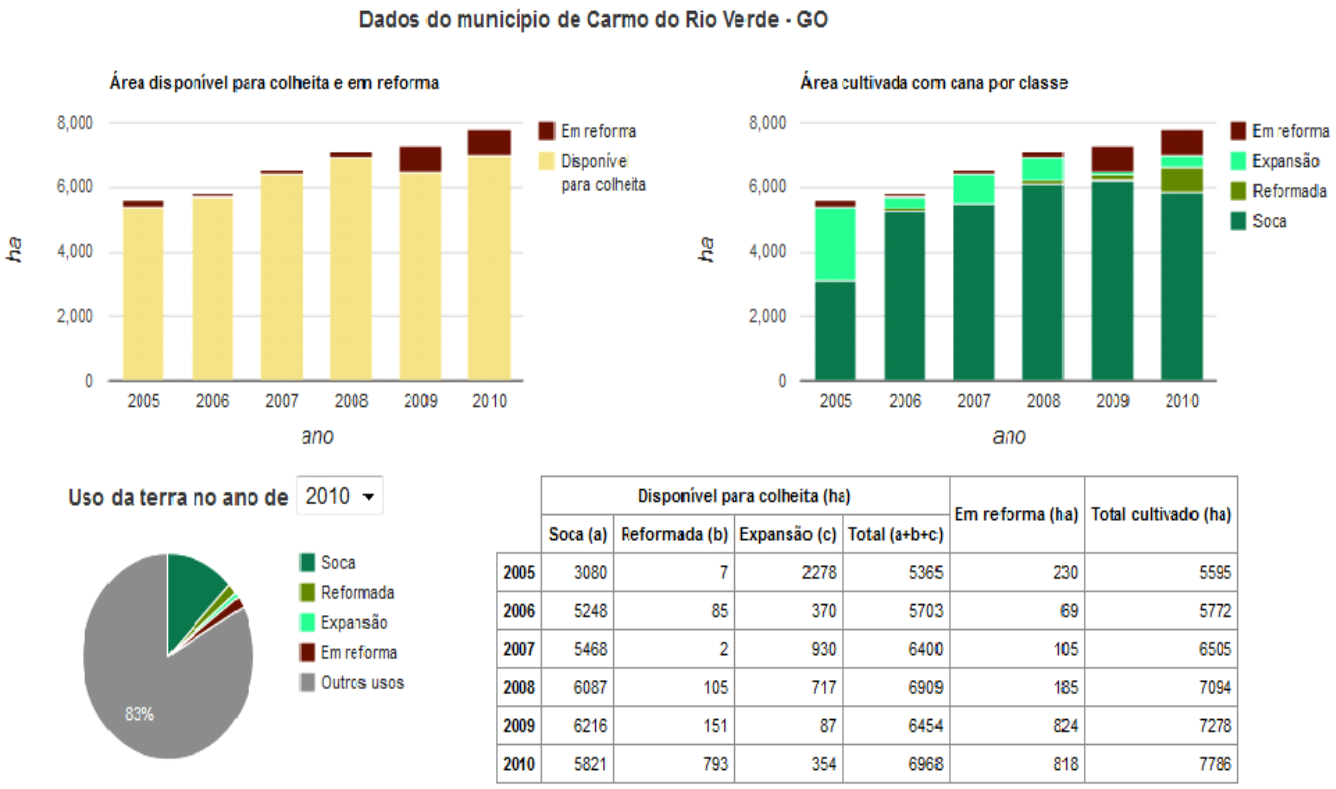

Figura 1 - Dados Históricos da cana-de-açúcar no Município de Carmo Rio Verde - 2005 a 2010 Fonte: Canasat

Nas questões relacionadas ao meio ambiente, segundo o Portal Municipal de Acompanhamento dos Objetivos do Milênio, o município: declara ter apresentado ocorrências impactantes, observadas com frequência no meio ambiente nos últimos 24 meses, com alteração ambiental (assoreamento do corpo d'água, queimadas e poluição do ar) que tenha afetado as condições de vida da população; possui Conselho Municipal de Meio Ambiente paritário, criado no ano de 2003 e não houve reuniões nos últimos 12 meses; não contou com recursos específicos para a área ambiental nos últimos 12 meses; possui Fundo Municipal de Meio Ambiente; e, não realiza licenciamento ambiental de impacto local.

Atualizando o Dashboard com os dados levantados de Carmo do Rio Verde, apresentamos os seguintes resultados para 2005.

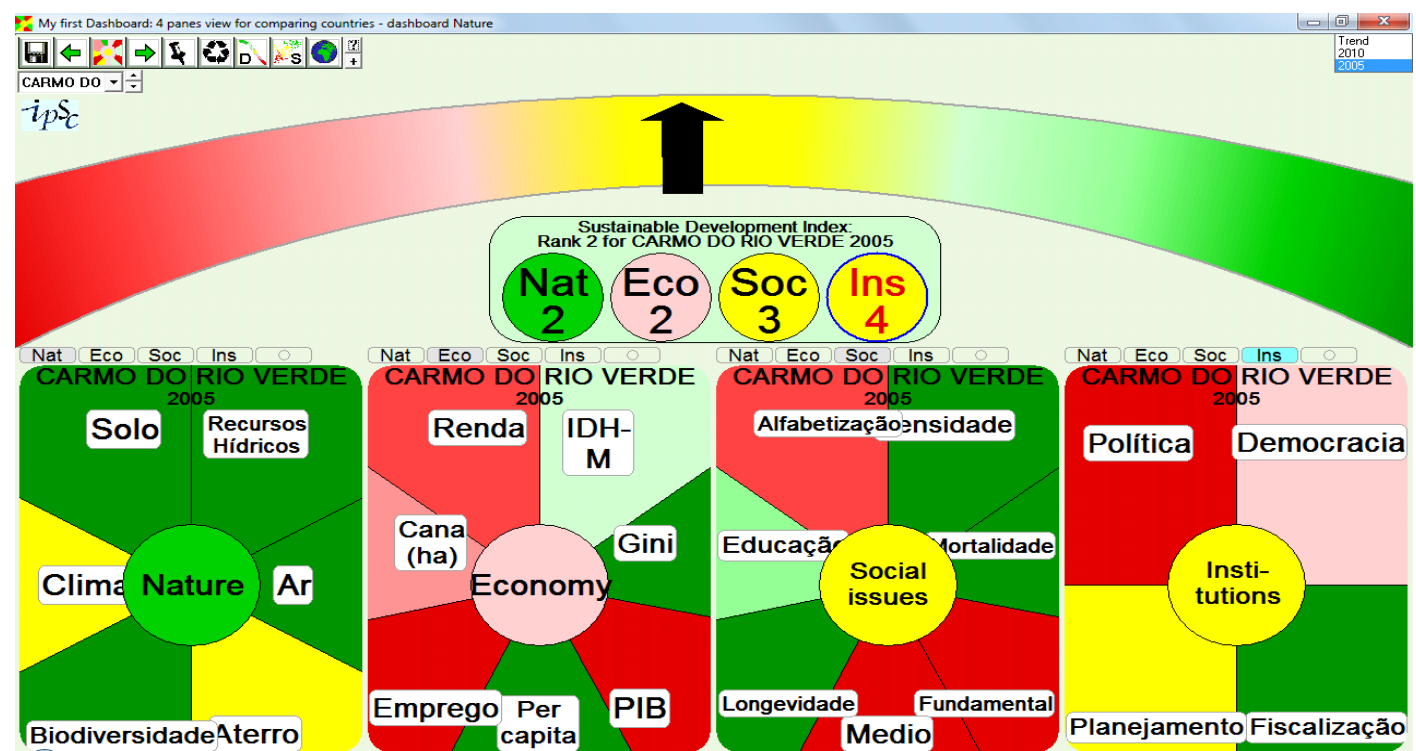

Figura 2 - Painel da Sustentabilidade do Município de Carmo do Rio Verde/2005

Fonte: As autoras 
Conforme apresentado na Figura 2, Carmo do Rio Verde, em 2005, encontrava-se em um nível mediano no que se refere ao Desenvolvimento Sustentável. Quando comparado com outros municípios da microrregião de Ceres, também sedes de usinas sucroalcooleiras (Goianésia, Itapaci, Itapuranga e Rubiataba), Carmo do Rio Verde estava também em segundo lugar no ranking.

Quando passamos a fazer a leitura mais minuciosa do painel, verificamos:

- Índice Ambiental (nature) - A preservação da biodiversidade, o estado do solo e os recursos hídricos foram os mais sustentáveis; ficando a desejar os fatores climáticos, o aterro sanitário e a coleta seletiva.

- Índice Econômico (Economy) - Embora seja o menos sustentável, ainda ficou em segundo lugar no ranking em comparação aos outros municípios sedes de usinas, necessitando de maior atenção o $\mathrm{PIB}$, o emprego e a renda. Isso demonstra uma baixa economia nos municípios da microrregião de Ceres em 2005. Os índices de GINI, per capita e IDH-Municipal estão sustentáveis.

- Índice Social (Social Issues) - A educação estava com muitos problemas, em 2005, em seus três níveis (alfabetização, ensino médio e ensino fundamental), mas o IDHM-Educação não apresentou tamanha deficiência. As taxas de longevidade, mortalidade e densidade demonstraram estar sustentáveis.

- Índice Institucional (Instituions) - Estes aspectos demonstraram uma grande diversidade, em que cada um apresentou uma performance. A preocupação maior deveria ser dada às políticas públicas e à democracia.

Também atualizando da mesma forma o Dashboard com dados de 2010, Carmo do Rio Verde demonstrou uma queda em relação aos outros municípios sedes de usina, pois passou do segundo para o quarto lugar, apresentando os seguintes resultados na Figura 3.

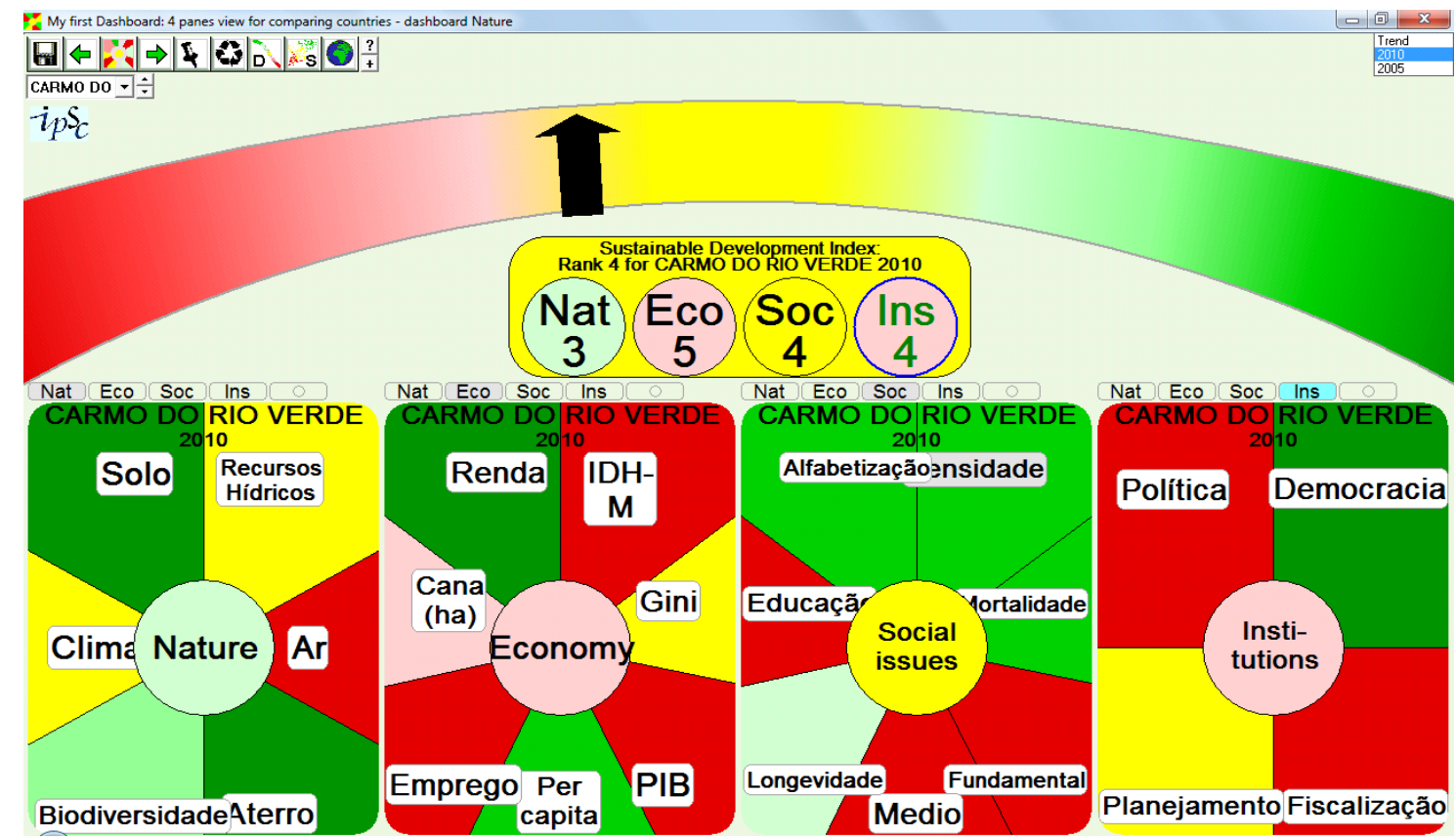

Figura 3 - Painel da Sustentabilidade do Município de Carmo do Rio Verde/2010

Fonte: As autoras

- Índice Ambiental (nature) - Os fatores climáticos, o estado do solo e os recursos hídricos mantiveram constantes. Houve grande queda de qualidade com o ar e uma pequena queda com a biodiversidade.

- Índice Econômico (Economy) - Esse foi o pior índice de todo o estudo. Demonstrou queda no IDH-M e no índice de GINI, e continuando insustentável nos demais índices. Só houve progresso nas rendas.

- Índice Social (Social Issues) - Nesse índice, os ensinos médio e fundamental não demonstraram melhoras, caindo bruscamente o IDH-M Educação; mas, melhorando o nível de alfabetização. A 
densidade demográfica, taxa de mortalidade e longevidade tiveram um pequeno decréscimo em relação aos dados anteriores (do ano de 2005).

- Índice Institucional (Instituions) - Esse foi o único índice, que, em relação aos outros municípios, se manteve constante. Mesmo assim demonstrou uma melhora política, mas uma queda brusca na fiscalização. As políticas públicas e o planejamento mantiveram constantes.

Quando comparamos os dois anos, para traçar o desenvolvimento do município e dizer se está ou não sustentável, chegamos à seguinte situação apresentada na Figura 4.

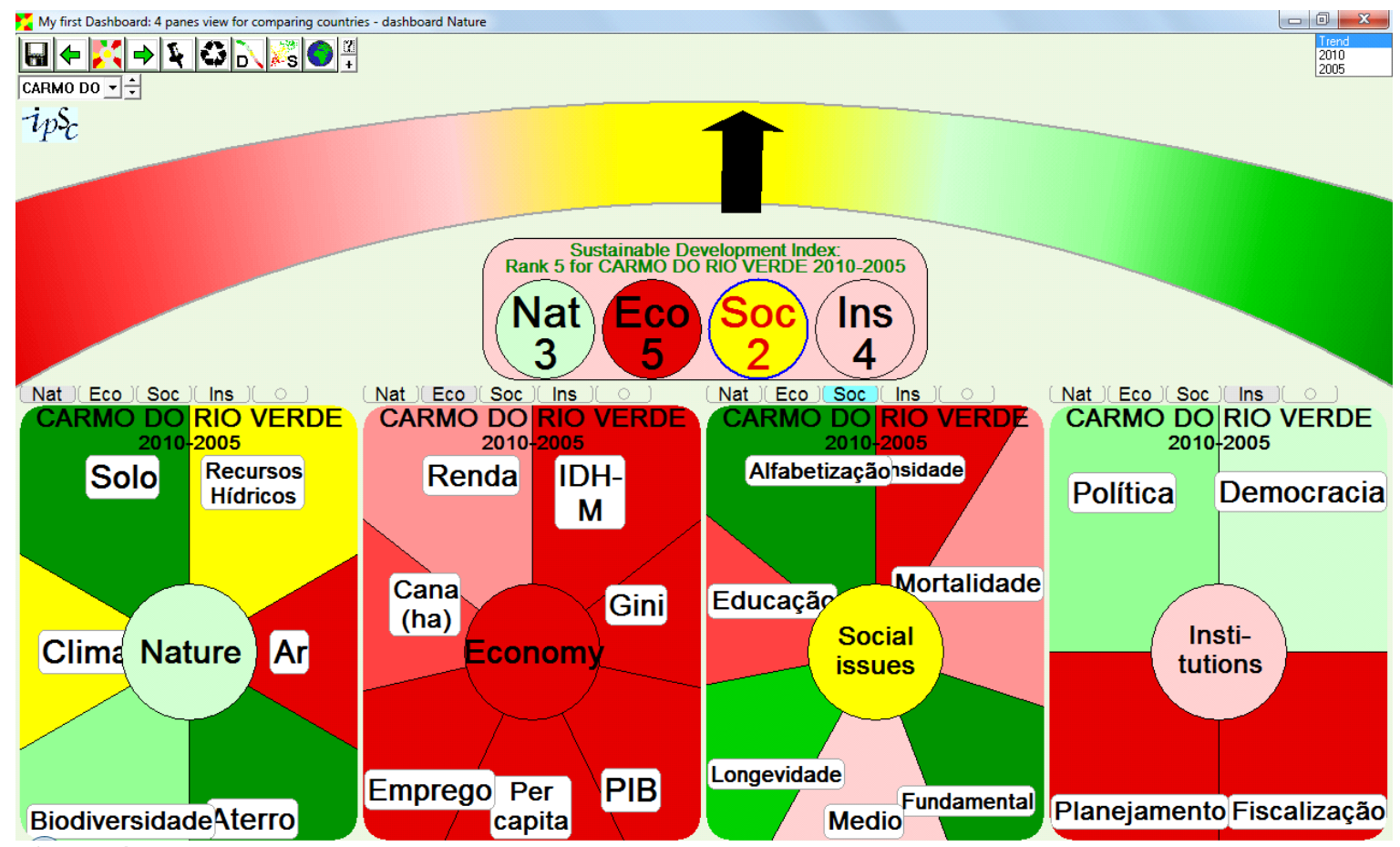

Figura 4: Painel do Desenvolvimento Sustentabilidade no Município de Carmo do Rio Verde 2005 - 2010

Fonte: A autora

Carmo do Rio Verde mostra certa sustentabilidade no índice ambiental, com baixo desempenho na qualidade do ar. Os aspectos sociais apresentam estabilidade, mas a área da região já está ficando pequena para o aumento populacional. $O$ ensino médio deve ser observado juntamente com a educação que têm demonstrado queda durante os anos observados. Dos aspectos institucionais, o planejamento e a responsabilidade fiscal foram os que demonstraram merecer maior atenção, pois a tendência é insustentável. O pior índice foi o econômico, apontando a insustentabilidade do município.

\section{CONSIDERAÇÕES FINAIS}

Ao demonstrar como se dá a nova configuração de uso do solo na região de Ceres, a partir da expansão recente da lavoura de cana, foi possível identificar que há fatores naturais que influenciam nesse processo, comprovando o conflito da expansão da fronteira agrícola causado entre as atividades produtivas ao uso do solo, particularmente entre a agricultura e a pastagem.

Da mesma forma, foi possível verificar que os impactos ao desenvolvimento sustentável se dão nas áreas ambientais, sociais, econômicas e institucionais, já que todas estão ligadas entre si, num sistema complexo. Este sistema complexo é que embasa o estudo para ser feito de forma interdisciplinar.

A evolução histórica da produção de cana-de-açúcar no Brasil apresentou crescimento nos últimos anos, reforçados por políticas públicas de incentivo à produção de álcool como fontes alternativas ao petróleo importado e ao uso eficiente da energia. 
Para a análise da sustentabilidade do município de Carmo do Rio Verde, diante da expansão canavieira e de todo incentivo público, a ferramenta que demonstra melhor adaptabilidade e eficácia na leitura dos dados em dimensões variadas é o Painel da Sustentabilidade. Os índices e indicadores utilizados no Dashboard of Sustainability (DS) ou Painel da Sustentabilidade identificam o perfil sustentável nas dimensões social, econômica, ambiental e institucional. Também foram identificadas as fontes disponíveis para captação de cada índice.

Por fim, por se tratar de um indicador mais subjetivo, para as políticas públicas foi desenvolvido um método de pontuação capaz de quantificá-las, possibilitando assim o seu uso no Dashboard of Sustainability.

Este estudo demonstrou que o município sofreu uma queda considerável no quesito Desenvolvimento sustentável (geral), uma vez que em 2005 ocupava uma posição de segunda colocada em comparação com outros municípios da mesma microrregião, também sedes de usinas sucroalcooleiras.

Quando detalhamos os índices estudados nos dois anos (2005 e 2010), concluímos que: no Índice Ambiental (nature), esse fator demonstrou ser totalmente insustentável em relação à qualidade do ar e apresentou uma pequena queda na biodiversidade, sendo que os fatores climáticos se mantiveram constantes nos dois anos analisados, os recursos hídricos, o aterro sanitário e a coleta seletiva são fatores que estão sustentáveis; no Índice Econômico (Economy) só a renda melhorou e a renda per capita continuou sustentável, deixando todos os outros indicadores insustentáveis; o Índice Social (Social Issues) demonstrou decréscimo de um ano para o outro em todos os seus indicadores, sendo a educação o que mais necessita de atenção. Por fim, o Índice Institucional (Instituions), demonstrou que as políticas públicas ainda são as mais insustentáveis, mesmo havendo melhora na participação democrática da população.

Diante de toda análise, é possível verificar no município de Carmo do Rio Verde uma despreocupação com a sustentabilidade, pois houve um decréscimo em todos os índices, sendo o índice institucional o que mais caiu. Isso mostra que a expansão da cana-de-açúcar afeta o município, e o governo não está atento aos fatores mais relevantes, pois o índice de políticas públicas é o mais insustentável. Os indicadores do Dashboard deixaram clara a tendência insustentável do Município, do ponto de vista econômico, por falta de planejamento e de fiscalização.

As transformações municipais caracterizadas pela expansão da fronteira agrícola refletem no perfil sustentável de cada cidade, podendo desequilibrar algumas das dimensões da sustentabilidade - social, econômica, ambiental ou institucional. Desta feita, para a aplicação de uma eficiente política pública, é de fundamental importância compreender todo o processo de expansão da fronteira agrícola e seus impactos no desenvolvimento sustentável.

\section{REFERÊNCIAS}

Agenda 21. (S/D) FPC. Resumo Agenda 21, mimeo, S/D

Baroni, M. (1992). Ambiguidades e deficiências do conceito de sustentabilidade. ERA, São Paulo, 32(2), 14-24, abr./jun.

Bellen, H.M.van. (2006). Indicadores de sustentabilidade: uma análise comparativa. (2 ed.). Rio de Janeiro, Editora FGV.

CMMAD - Comissão Mundial sobre Meio Ambiente e Desenvolvimento.(1991). Nosso futuro comum. (2 ed.) Rio de Janeiro: Editora da Fundação Getúlio Vargas. 
IPEA (Instituto de Pesquisa Econômica Aplicada). (2010). Brasil em Desenvolvimento: Estado, planejamento e políticas públicas. 270p, 3v. IPEA, Brasília. In: Instituições participativas $e$ Políticas Públicas no Brasil: características e evolução nas últimas duas décadas. 3, parte IV, cap. 21, 564-585.

Martins, J.de S. (1975). Capitalismo e tradicionalismo: estudos sobre as contradições da sociedade agrária no Brasil. São Paulo. Editora Pioneira.

Marx, K.(1885/86). O capital. Crítica da economia política. (2. ed.). São Paulo. Editora Nova Cultural.

Miziara, F. (2000). Condições estruturais e opção individual na formulação do conceito de "Fronteira Agrícola". In: Silva, L.S. da (org.). Relações da Cidade-Campo: Fronteiras. Goiânia: Editora UFG, 273-289.

.(2006). Expansão de fronteiras e ocupação do espaço no cerrado: o caso de Goiás. In: Guimarães, L. D. A, Silva, M. A. D, Anacleto, T. C. (org.). Natureza Viva Cerrado: caracterização e conservação. Cap.VII,(1.ed.) Goiânia: Editora UCG.

Morin, E.(2005). Introdução ao pensamento complexo. Tradução do francês: Eliane Lisboa. Porto Alegre. Editora Meridional Sulina.

Najberg, E. (2003). Análise dos fatores que dificultam a implementação da Política Ambiental do Plano de Desenvolvimento Sustentável do Rio Grande do Norte. São Paulo: EAESP/FGV, 406 p. (Tese de Doutorado apresentada ao Curso de Pós-Graduação da EAESP/FGV, Área de concentração: Organização, Recursos Humanos e Planejamento, com Domínio conexo em Planejamento Urbano e Políticas Públicas.

Sachs, I. (2003). Inclusão social pelo trabalho: desenvolvimento humano, trabalho decente e o futuro dos empreendedores de pequeno porte no Brasil. (2. ed.). Rio de Janeiro. Garamond.

Secchi, L.(2010). Políticas públicas: conceitos, esquemas de análise, casos práticos. São Paulo. Cengage Learning.

Vergara, S.C.(2008). Métodos de Pesquisa em Administração. (4. ed.). São Paulo. Editora Atlas.

Recebido em: 19/10/2011

Publicado em: 21/12/2012 